\title{
Lumbar facet injection for the treatment of chronic piriformis myofascial pain syndrome: 52 case studies
}

This article was published in the following Dove Press journal:

Patient Preference and Adherence

20 August 2014

Number of times this article has been viewed

\author{
Jen-Ting Huang' \\ Han-Yu Chen ${ }^{2}$ \\ Chang-Zern Hong ${ }^{2}$ \\ Ming-Ta $\operatorname{Lin}^{3}$ \\ Li-Wei Chou ${ }^{4,5}$ \\ Hsin-Shui Chen ${ }^{6,7}$ \\ Chien-Tsung Tsai ${ }^{8}$ \\ Wen-Dien Chang'
}

'Department of Orthopedic Surgery, Taichung Veterans General Hospital, ${ }^{2}$ Department of Physical Therapy, Hung-Kuang University, Sha Lu ${ }^{3}$ Kuan-Ta Rehabilitation and Pain Clinic, Taichung, Taiwan; ${ }^{4}$ Department of Physical Medicine and Rehabilitation, China Medical University Hospital, ${ }^{5}$ School of Chinese Medicine, College of Chinese Medicine, China Medical University, Taichung, Taiwan;

${ }^{6}$ Department of Rehabilitation Medicine, Bei-Gang Hospital, School of Medicine, China Medical University, Yun-Lin, Taiwan; ${ }^{7}$ School of Medicine, College of Medicine, China Medical University, Taichung, Taiwan; ${ }^{8}$ Department of Rehabilitation Medicine, Da-Chien Hospital, Miao-Li City, Taiwan; ${ }^{9}$ Department of Sports Medicine, China Medical University, Taichung, Taiwan
Correspondence: Chien-Tsung Tsai Department of Rehabilitation Medicine, Da-Chien Hospital, Miao-Li, Taiwan Email pmr.tsai@msa.hinet.net
Background and aims: The aim of this study was to demonstrate the effectiveness of lumbar facet joint injection for piriformis myofascial pain syndrome.

Methods: Fifty-two patients with chronic myofascial pain in the piriformis muscle each received a lumbar facet injection into the ipsilateral L5-S1 facet joint region, using the multiple insertion technique. Subjective pain intensity, trunk extension range, and lumbar facet signs were measured before, immediately after, and 2 weeks after injection. Thirty-six patients received follow-up for 6 months.

Results: Immediately after the injection, 27 patients $(51.9 \%)$ had complete pain subsidence, 19 patients $(36.5 \%)$ had pain reduction to a tolerable level, and only 6 patients $(11.5 \%)$ had no pain relief to a tolerable level. Mean pain intensity was reduced from $7.4 \pm 0.9$ to $1.6 \pm 2.1$ after injection $(P<0.01)$. This effectiveness lasted for 2 weeks in 49 patients $(94.2 \%)$, and lasted for approximately 6 months in $35(97.2 \%)$ of 36 patients. The mean range of motion increased from $13.4 \pm 6.8$ degrees to $22.1 \pm 6.0$ degrees immediately after injection, and further increased 2 weeks and 6 months later. Immediately after injection, 45 patients $(86.5 \%)$ had no facet sign. In addition, $90.4 \%$ and $94.4 \%$ of patients had no facet sign after 2 weeks and after 6 months, respectively.

Conclusions: It is important to identify the possible cause of piriformis myofascial pain syndrome. If this pain is related to lumbar facet lesions, lumbar facet joint injection can immediately suppress piriformis myofascial pain symptoms. This effectiveness may last for at least 6 months in most patients. This study further supports the importance of eliminating the underlying etiological lesion for complete and effective relief of myofascial pain syndrome.

Keywords: facet joints, injection, piriformis, chronic myofascial pain, pain intensity, range of motion, lumbar facet sign

\section{Introduction}

In a broad sense, piriformis syndrome has been defined as a pain syndrome related to the piriformis muscle, including all pathological lesions of the piriformis itself, such as those caused by myofascial pain, anatomical variations, hypertrophy, trauma ${ }^{1-7}$ and any extrinsic lesion causing pain similar to piriformis syndrome. ${ }^{1,6}$ However, the traditional piriformis syndrome has been shown to be limited to pain syndrome directly due to sciatic nerve entrapment causing compression of the piriformis muscle. ${ }^{1,3,6,8}$ The term piriformis myofascial pain syndrome (PMPS) has been used for a pain syndrome caused by myofascial trigger points (MTrPs) of piriformis muscle. ${ }^{3,6}$ PMPS can be caused by various lesions including, for example, herniated lumbar discs, degenerative lumbar disc lesions, lumbar facet syndrome, trochanteric bursitis, sacroiliac joint dysfunction, and endometriosis. ${ }^{1,9-12}$ 
Clinically, piriformis syndrome with sciatic nerve entrapment is different from PMPS. In mild or early cases of sciatic nerve entrapment, the patient may have tingling in the region of the peroneal and/or tibial nerve territory as a consequence of direct irritation to the sciatic nerve, but the symptoms may include severe pain and paresthesia in the territories of the peroneal and tibial nerves in severe cases. ${ }^{8}$ On the other hand, the pain due to PMPS is a type of referred pain (but frequently not tingling unless superimposed with radiculopathy) from the MTrP of the piriformis muscle and is usually limited to the posterior thigh above the knee and does not occur in the legs or feet. ${ }^{3,6}$

Myofascial pain syndrome is typically elicited by MTrPs. ${ }^{6}$ An MTrP is a hyperirritable spot in a palpable taut band of skeletal muscle fibers. ${ }^{6}$ An active MTrP is characterized by spontaneous pain or pain during movement, and a latent MTrP is a tender spot with pain only in response to compression. The pathophysiology of MTrP has been clarified and is now widely accepted. ${ }^{12-21}$ The current definition of MTrP is the accumulation of sensitized nociceptors in the end plate zone of a palpable taut band of skeletal muscle fibers. ${ }^{22}$ The most important strategy to achieve immediate and prolonged relief of the pain due to MTrP is to identify and eliminate the etiological factor. ${ }^{14,15}$

Clinically, pain due to PMPS can be aggravated by compression of the MTrP of piriformis muscle, and the pain can be referred to the posterior thigh. In addition, the PMPS pain can also be elicited or aggravated by compression or any irritation (provoking test) to the etiological lesion site, such as the sacroiliac joint, the subtrochanteric bursa, or the lumbar facet joint. Lumbar facet lesions are probably the most common extrinsic causes of PMPS. In such cases, the pain can be reproduced during performance of a lumbar facet test, ${ }^{23,24}$ and the pain can be relieved by appropriate treatment of the lumbar facet lesion. ${ }^{10,14}$ In clinical practice, pain involving the MTrP in the piriformis muscle is frequently caused by a degenerative disc at the L5-S1 level. ${ }^{25}$ The first choice of treatment for lumbar degenerative disc disease is physical therapy including pelvic traction. If the pain cannot be suppressed effectively by pelvic traction, a lumbar facet joint injection can be a next choice prior to considering surgical intervention for disc replacement. However, the effectiveness of facet injection is still controversial. ${ }^{26-28}$ In a previous study, ${ }^{29}$ it was shown that shoulder pain related to cervical facet lesions could be successfully controlled for a prolonged period. In our previously published case report, ${ }^{30}$ we found that lumbar facet injections were useful for releasing PMPS related to facet joint lesions. The objective of the clinical study reported here was to demonstrate the effectiveness of the lumbar facet injection for PMPS. In this study, a special technique was used for lumbar facet injections.

\section{Materials and methods}

Patients with chronic pain due to PMPS each received a lumbar facet injection into the ipsilateral L5-S1 facet joint. Subjective pain intensity, trunk extension range, and the lumbar facet sign were assessed before, immediately after, and 2 weeks after injection. Thirty-six patients received follow-up assessments about 6 months after injection.

\section{Subjects}

Inclusion criteria for this study were as follows:

1. The patient had chronic pain in the gluteal region (due to active MTrP in the medial aspect of the piriformis muscle identified following the Travell and Simons technique) ${ }^{6}$ for longer than 6 months. The diagnosis of MTrP is based on the existence of a tender spot in a taut band deep in the muscle. When compressed on affected muscle, pain, and sometimes referred pain, may be elicited with the character and location of pain similar to the clinical usual complaints of patients with $\mathrm{MTrP}$ (pain recognition).

2. The patient had intolerable MTrP pain defined as a score of 6 or higher on a scale of 0 to 10 , where 0 indicates no pain and 10 indicates the worst pain ever experienced.

3. The patient had a positive lumbar facet sign with pain referred to ipsilateral gluteal region similar to that elicited by compression of the medial MTrP in the piriformis muscle (pain recognition). ${ }^{6}$

4. The patient had been previously treated with oral medication (analgesic and/or nonsteroidal anti-inflammatory drug) and physical therapy including heat and pelvic traction for longer than 2 months with unsatisfactory results.

5. The patient had a significant decrease of the intervertebral disc space at L5-S1 in regular X-ray findings.

Exclusion criteria included 1) previous surgical intervention in the spine or hip, 2) previous local injection to the lumbar spine facet joint, 3) current treatment with a narcotic drug, 4) impairment of cognition or speech, or 5) current pregnancy.

In total, 63 patients were selected following the above criteria. However, 8 patients refused to have injection therapy. Another 3 patients received injections but did not return for further assessment 2 weeks later. Finally, 52 patients were enrolled in this study. Six months later, 36 of these patients returned for further assessment. 
Among the 52 enrolled patients, 36 had low back pain, and 14 had ipsilateral sciatica. In addition to subjective pain in the ipsilateral lower limb, 2 patients had motor weakness, 7 patients had sensory deficits, and 10 patients had reduced deep tendon reflexes according to the ankle jerk test. Electrodiagnostic tests were performed on all 14 patients with sciatica and on 21 other patients with no sciatica, but only 2 patients with weakness had positive findings suggesting chronic L5 and S1 radiculopathy. Plain X-ray films were obtained for all 52 subjects. As per an inclusion criterion, every subject had significant decrease the intervertebral space at L5-S1 level. Other patient findings included marginal osteophytes in some lumbar vertebrae. MRI studies were performed in 22 patients (including the 14 sciatica patients), and all patients had reduced L5-S1 disc space, but only 8 had a mild to moderate degree of disc protrusion.

Tables 1 and 2 show the main characteristics of the 52 patients (Table 1) who completed the 2-week study and the 36 patients (Table 2 ) who completed the follow-up assessment 6 months after injection.

\section{Lumbar facet joint injection procedure with multiple insertions to the perifacet region}

Each patient was asked to stay in a prone position with a pillow under his or her pelvis. The site for the needle penetration was marked at the midpoint between the right posterior superior iliac spine and the $\mathrm{L} 5$ vertebra spinous process. The location of the L5-S1 facet joint was just beneath this point. An anesthetic solution containing $1 \mathrm{~mL}$ triamcinaline acetonide ( $40 \mathrm{mg} / \mathrm{mL}$ ) and $2 \mathrm{~mL}$ lidocaine (1\%) in a $5 \mathrm{cc}$ syringe connected to a 23 gauge needle with a length of $2^{3 / 4}$ inches was used for the injection. After sterilization, the syringe was

Table I Characteristics of the 52 patients who completed the 2-week study

\begin{tabular}{|c|c|c|c|c|}
\hline \multirow{3}{*}{\multicolumn{2}{|c|}{$\begin{array}{l}\text { Number of subjects } \\
\text { Age (years), mean } \pm S D\end{array}$}} & Male & Female & All subjects \\
\hline & & 40 & 12 & 52 \\
\hline & & $54.0 \pm 10.4$ & $59.0 \pm 6.4$ & $52.3 \pm 9.7$ \\
\hline \multirow[t]{2}{*}{ Side } & Right, $\mathrm{n}$ & 20 & 7 & 27 \\
\hline & Left, $\mathrm{n}$ & 20 & 5 & 25 \\
\hline \multicolumn{2}{|c|}{ With low back pain, $\mathrm{n}$} & 29 & 7 & 36 \\
\hline \multicolumn{2}{|c|}{ With ipsilateral sciatica, $\mathrm{n}$} & 11 & 3 & 14 \\
\hline \multicolumn{2}{|c|}{$\begin{array}{l}\text { With ipsilateral } \\
\text { weakness, } n\end{array}$} & 2 & 0 & 2 \\
\hline \multicolumn{2}{|c|}{$\begin{array}{l}\text { With ipsilateral sensory } \\
\text { deficit, } n\end{array}$} & 5 & 2 & 7 \\
\hline \multicolumn{2}{|c|}{$\begin{array}{l}\text { With reduced tendon } \\
\text { reflex, } \mathrm{n}\end{array}$} & 9 & I & 10 \\
\hline
\end{tabular}

Abbreviation: SD, standard deviation.
Table 2 Characteristics of 36 patients who completed the follow-up assessment 6 months after the injection

\begin{tabular}{llll}
\hline & Male & Female & All subjects \\
\hline Number of subjects & 28 & 8 & 36 \\
Age (years), mean \pm SD & $54.3 \pm 10.8$ & $57.0 \pm 6.6$ & $51.4 \pm 9.9$ \\
Side Right, $\mathrm{n}$ & 14 & 5 & 19 \\
$\quad$ Left, $\mathrm{n}$ & 14 & 3 & 17 \\
With low back pain, $\mathrm{n}$ & $2 \mathrm{I}$ & 4 & 25 \\
With ipsilateral sciatica, $\mathrm{n}$ & 9 & 2 & $\mathrm{II}$ \\
With ipsilateral weakness, $\mathrm{n}$ & $\mathrm{I}$ & 0 & $\mathrm{I}$ \\
With ipsilateral sensory deficit, $\mathrm{n}$ & 4 & 2 & 6 \\
With reduced tendon reflex, $\mathrm{n}$ & 8 & $\mathrm{I}$ & 9 \\
\hline
\end{tabular}

Abbreviation: SD, standard deviation.

held by the dominant hand gently with the thumb and middle finger in the anterior position and the index finger controlling the end portion of syringe, similar to Hong's technique for MTrP injection. ${ }^{14,21,25}$ Mapping the depth of bony structures at and near the facet joint was important. The needle was moved to penetrate through skin and soft tissues under the marked spot slowly and perpendicularly until it encountered the bone; it was then pulled out for a few $\mathrm{mm}$ and reinserted about $1 \mathrm{~mm}$ in another direction. This procedure was repeated until a narrow dip of the facet joint could be felt. At this point, approximately $1 \mathrm{~mL}$ of solution was pushed into this space by the index finger on the end of the syringe. If the solution couldn't be pushed out due to strong resistance, the above procedure was repeated and the needle tip moved to where the solution could be pushed out smoothly. In our clinical experience, usually 1-2 $\mathrm{mL}$ of solution can be pushed out without any significant resistance if the facet joint is encountered. This technique requires that the accurate location of the needle tip can be detected via the sensation of the thumb and index finger holding the syringe.

During the multiple insertion procedure, A drop of anesthetic solution was was injected if the patient reported any sensation of pain or if the patient expressed any feeling of pain by making a sudden minor movement of the trunk or a verbal noise in response to the needle insertion. Pain sensations may indicate that a sensitized nociceptor was encountered by the needle tip. ${ }^{22,25,31}$ All patients tolerated the procedure well with no side effects after the procedure. Occasionally bleeding was noticed from the opening of the needle penetration but was stopped easily by a firm compression over the wound opening.

Five additional patients in our clinic (not included in the 52 selected subjects) were referred to receive a facet injection under fluoroscopic guidance as per the patients' preference. The comparison of outcome assessments was performed at our clinic twice prior to the procedure and after injection. 
Unfortunately, the results were not any better than ours. In fact, the times taken for the procedure were much longer than those of our study. All of these patients complained of pain and discomfort for more than 2 days after the injection and had to return to our clinic to continue physical therapy.

\section{Outcome assessments}

\section{Numerical pain rating scale}

The subjective pain intensity of the piriformis MTrP was assessed with a verbally reported numerical pain rating scale ranging from 0 to 10 , where 0 indicates no pain and 10 indicates the worst pain ever experienced. Patients were also instructed that a pain rating of 6 out of 10 or higher was considered intolerable pain. Patients reported pain intensity just before the injection and immediately after the injection. The patients could get out of bed immediately after the injection. Usually, the patient was requested to walk around to further confirm the intensity of the pain after injection.

\section{Range of motion of trunk extension}

The range of motion of trunk extension was assessed in a prone position (without pillow under the pelvis) before and immediately after the injection and during follow-up assessments. The patient was asked to push up with the upper limbs to rise the head and upper trunk from the table. While the patient was asked to push up with upper limbs to rise up the head and upper trunk from the table, they were asked to try their best to focus on the point of back pain or the limitation of mobility. The angle between the horizontal table surface and the raised upper trunk was measured with a goniometer.

\section{Lumbar facet provoking test (facet sign)}

The lumbar facet provoking test to assess the facet $\operatorname{sign}^{24}$ was performed in a standing position. The patient was asked to rotate the upper trunk to the painful side followed by hyperextending the trunk backward as much as possible. If the gluteal pain (piriformis MTrP pain) developed at the terminal range, it was considered a positive facet sign.

All the above assessments could be performed as part of a routine physical examination without any special equipment or devices.

\section{Statistical analysis}

Repeated measures one-way ANOVAs with Bonferroni multiple comparison tests were applied to assess the differences among the preinjection data, the corresponding postinjection data, and the follow-up data. The chi-square test was used to test differences in the facet joint signs preinjection and postinjection. A $P$ value of less than 0.01 was considered statistically significant.

\section{Results}

Table 3 shows the number of patients with different pain levels before, immediately after, 2 weeks after, and 6 months after injection. Immediately after injection, 46 patients $(88.5 \%)$ reported that pain intensity had reduced to tolerable levels (between 0 and 5 out of 10 on the pain scale). Only 6 patients $(11.5 \%)$ reported pain intensity that was still intolerable ( 6 or higher out of 10 on the pain scale), while only 2 patients $(3.8 \%)$ had no improvement at all. No patient reported increased pain after injection. Further improvement could be seen at the 2-week and 6-month follow-up assessments. Six months after injection, only one patient reported that pain remained at the intolerable level. Again, further improvement was noted at 2 weeks and 6 months after injection. Six months after injection, $97 \%$ of patients had pain levels reduced to less than 6 out of 10 on the pain scale. As shown in Table 4, the mean pain intensity decreased significantly $(P<0.01)$ immediately, 2 weeks after, and 6 months after the injection.

Immediately after the injection, 45 patients $(86.5 \%)$ had an increased range of motion in trunk extension. Two weeks after the injection, 33 patients $(63.5 \%)$ had further improvement in range of motion, range of motion for 16 patients $(30.8 \%)$ remained unchanged, and only 3 patients $(5.8 \%)$ had reduced range of motion. Six months after the injection, 16 patients (44.4\%) had further improvement in the range of motion, range of motion for 13 patients $(36.1 \%)$ remained unchanged, and 7 patients (19.4\%) had reduced range of motion.

The mean range of motion in trunk extension increased progressively and significantly $(P<0.01)$ immediately after, 2 weeks after, and 6 months after the injection (Table 4). We also found further improvement in trunk mobility from the

Table 3 Changes in pain intensity after facet joint injection

\begin{tabular}{lllll}
\hline & $\begin{array}{l}\text { Before injection } \\
(\mathbf{n}=\mathbf{5 2})\end{array}$ & $\begin{array}{l}\text { Immediately after } \\
\text { injection } \mathbf{( n = 5 2 )}\end{array}$ & $\begin{array}{l}\text { 2 weeks after } \\
\text { injection }(\mathbf{n}=\mathbf{5 2})\end{array}$ & $\begin{array}{l}\mathbf{6} \text { months after } \\
\text { injection }(\mathbf{n}=\mathbf{3 6})\end{array}$ \\
\hline $\begin{array}{l}\text { Number (\%) of patients with } \\
\text { Pain intensity 0/10 }\end{array}$ & $0(0 \%)$ & $27(51.9 \%)$ & $27(51.9 \%)$ & $22(61.1 \%)$ \\
Pain intensity I/10 to $5 / 10$ & $0(0 \%)$ & $19(36.5 \%)$ & $22(42.3 \%)$ & $13(36.1 \%)$ \\
Pain intensity 6/10 to $9 / 10$ & $52(100 \%)$ & $6(11.5 \%)$ & $3(5.8 \%)$ & $1(2.8 \%)$ \\
\hline
\end{tabular}


time immediately after the injection to the time of follow-up 2 weeks and 6 months after injection.

As shown in Table 4, all 52 patients had a positive facet sign before injection, and 45 of these patients (86.5\%) came to have a negative sign immediately after the injection. Only 7 patients (13.5\%) still had a positive facet sign immediately after the injection. Two weeks after the injection, 2 of these 7 patients had a negative sign. Six months after the injection, 2 of 36 patients continued to have a positive facet sign. For no patient was the facet sign assessment observed to have worsened.

\section{Discussion}

This study has demonstrated the therapeutic effectiveness of lumbar facet joint injection with a special multiple insertion technique to eliminate chronic piriformis MTrP pain. This study further confirms the importance of eliminating the underlying etiological lesion for immediate and complete relief of activated myofascial pain. The diagnosis of PMPS is usually based on subjective complaints and the findings of clinical examination. ${ }^{6}$ Two MTrPs can be identified in the piriformis muscle. The medial one is near the pathway of the sciatic nerve, and is the one that frequently caused PMPS. Treatments for PMPS itself include noninvasive physical modalities, minimally invasive needling and injection techniques, and invasive surgical procedures. ${ }^{1,6}$ However, the pain due to MTrP of piriformis may be suppressed temporarily, but frequently recurs if the underlying etiological lesion is not treated appropriately. The cause of PMPS can be related to or due to lumbar spinal lesions, sacral spinal lesions, sacroiliac lesions, pelvic lesions, or hip joint lesions, and so on, and the most common cause is a lumbar facet lesion at the level of L5-S1.6,14,25 Lumbar facet lesions can cause MTrP pain in gluteal muscles including piriformis muscle. ${ }^{14,24,25,32}$ In many cases, the facet joint instability (posterior segment lesion of spine) can be caused by the collapsed (desiccated) intervertebral disc (anterior segment lesion) a few years after the ligament injury (rupture of annulus fibrosus) due to disc herniation. In a few cases, the facet instability can be caused by a direct trauma. Any injury to the facet joint capsule can cause pain in the facet joint. ${ }^{23}$ When the L5-S1 disc space is reduced, the upper part of the L5-S1 facet joint (at a lower margin of the L5 vertebra) may slide down and cause compression to the lower part of the L5-S1 facet joint (upper margin of the S1 vertebra) so that the sensitized nociceptors in the L5-S1 facet joint transmit impulses to the spinal cord to cause referred pain to the piriformis muscle. Therefore, if the L5-S1 facet joint is treated, the pain due to PMPS can be suppressed.

When the facet joint is unstable due to ligament laxity, a rotary movement of the corresponding vertebral segments followed by hyperextension can induce extreme irritation to the injured ligament so that a pain in the facet joint itself and a referred pain to a certain corresponding region can be elicited. This is a "positive facet sign". ${ }^{24}$

The first choice of treatment for a lumbar facet lesion is a physical therapy program including the local thermotherapy of the lumbar spine followed by a lumbar traction with the hips flexed and the legs elevated. ${ }^{33,34}$ Manual therapy such as mobilization or manipulation may be effective. ${ }^{33,35}$ In case of a poor response to conservative physical therapy, lumbar facet joint injection is an option to treat a lumbar facet lesion prior to considering surgical intervention, such as disc replacement. Lumbar facet joint injection is usually under the guidance of fluorescent direction. ${ }^{26,27}$ To avoid radiation exposure, we developed a "blind injection technique". This technique is fast, less expensive, and is usually successful. However, if an ultrasonography is available, the ultrasound guidance may be a better way to perform this procedure ${ }^{36}$ However, even under the guidance of fluorescent or sonographic direction, lumbar facet joint injection frequently requires several needle insertions to get into the narrow facet joint space. With a skillful, well-practiced technique, one can get into the facet joint space with only a few

Table 4 Assessments before, immediately after, 2 weeks after, and 6 months after injection

\begin{tabular}{|c|c|c|c|c|}
\hline & $\begin{array}{l}\text { Before injection } \\
(n=52)\end{array}$ & $\begin{array}{l}\text { Immediately after } \\
\text { injection }(n=52)\end{array}$ & $\begin{array}{l}2 \text { weeks after } \\
\text { injection }(n=52)\end{array}$ & $\begin{array}{l}6 \text { months after injection } \\
(n=36)\end{array}$ \\
\hline Pain intensity, mean $\pm S D$ & $7.4 \pm 0.9$ & $1.6 \pm 2.1^{*, a}$ & I. $3 \pm 2.0 *, a$ & $0.9 \pm \mathrm{I} .5^{*, \mathrm{a}}$ \\
\hline $\begin{array}{l}\text { Range of trunk extension, mean } \pm S D \\
\text { (degrees) }\end{array}$ & $\begin{array}{l}13.4 \pm 6.8 \\
(n=52)\end{array}$ & $\begin{array}{l}22.1 \pm 6.0 *, a \\
(n=52)\end{array}$ & $\begin{array}{l}26.5 \pm 5.6 * *, a \\
(n=52)\end{array}$ & $\begin{array}{l}28.6 \pm 4.6 * *, a \\
(n=36)\end{array}$ \\
\hline \multicolumn{5}{|l|}{ Lumbar facet sign } \\
\hline Positive, n (\%) & $52(100 \%)$ & $7(13.5 \%)^{*, b}$ & $5(9.6 \%)^{*, b}$ & $2(5.6 \%)^{*, b}$ \\
\hline Negative, n (\%) & $0(0 \%)$ & 45 (86.5\%) & 47 (90.4\%) & 34 (94.4\%) \\
\hline
\end{tabular}

Note: $* P<0.01$ compared with result before the injection and $* * P<0.01$ compared with result immediately after the injection. Statistical tests used: arepeated measures one-way analysis of variance and bchi-square test.

Abbreviation: SD, standard deviation. 
needle insertions even if the blind technique is used..$^{29,36} \mathrm{We}$ also apply a multiple injection technique similar to that developed by Travell for MTrP injection., ${ }^{3,6,21}$ The reason for the multiple needle insertion technique is to attempt to reach multiple sensitive loci (nociceptors) in the pain region as much as possible..$^{14,25,29}$ When sensitive nociceptors are encountered, the strong needle stimulation (high pressure) can cause impulses (action potentials) transmitted to the spinal cord via sensory pathways to turn on the descending pain inhibitory system. ${ }^{14,25,31}$ The descending pain inhibitory system is the most important intrinsic pain control mechanism. ${ }^{37-42}$ So that the pain can be eliminated immediately after needling. The injection of corticosteroid can further suppress the inflammation in the facet joint region.

This pilot clinical case study is limited in some aspects. The most important limitations include the lack of a placebo control group and the lack of double blind measurements of study design. The outcome assessments were simple clinical measurements. More accurate objective measures are required to provide better certitude. From a statistical point of view, a control group to provide blindness is important if the outcome assessments include subjective evaluation. However, in this study, we also provided objective blind evaluation. This design could eliminate significant subjective bias. However, this preliminary study could stimulate future well-designed studies to further explore this simple and effective technique.

\section{Conclusion}

Chronic recurrent PMPS with a positive facet sign indicating that the etiological lesion is the lumbar L5-S1 facet lesion can be effectively treated with a lumbar facet injection. The simple, blind, multiple insertion technique can provide immediate and complete pain relief for a significant period of time after injection in most cases. This case study further supports the importance of treating the underlying etiological lesion appropriately in order to provide immediate and effective pain relief of chronic myofascial pain.

\section{Disclosure}

All the authors herewith certify that we have no nonfinancial or commercial, proprietary, or financial interest in the products or companies described in the manuscript. The authors did not receive grants or a consultant honorarium to conduct the study, write the manuscript, or otherwise assist in the development of the abovementioned manuscript.

\section{References}

1. Cummings M. Piriformis syndrome. Acupunct Med. 2000;18:108-121.

2. Colmegna I, Justiniano M, Espinoza LR, Gimenez CR. Piriformis pyomyositis with sciatica: an unrecognized complication of "unsafe" abortions. J Clin Rheumatol. 2007;13:87-88.

3. Hong CZ. Piriformis syndrome. In: Common Problems in Pain Management. Chicago: Year Book Medical Publishers; 1990:183-187.

4. Parziale JR, Hudgins TH, Fishman LM. The piriformis syndrome. Am J Orthop. 1996;25:819-823.

5. Porta M. A comparative trial of botulinum toxin type A and methylprednisolone for the treatment of myofascial pain syndrome and pain from chronic muscle spasm. Pain. 2000;85:101-105.

6. Travell JG, Simons DG. Myofascial pain and dysfunction: the trigger point manual. Vol 2. Baltimore: Lippincott Williams \& Wilkins, 1992.

7. Windisch G, Braun EM, Anderhuber F. Piriformis muscle: clinical anatomy and consideration of the piriformis syndrome. Surg Radiol Anat. 2007;29:37-45.

8. Robinson DR. Piriformis syndrome in relation to sciatic pain. Am J Surg. 1947;73:355-358.

9. Benzon HT, Katz JA, Benzon HA, Igbal MS. Piriformis syndrome. Anesthesiology. 2003;98:1442-1448.

10. Kao MJ, Kuan TS, Hsieh YL, Yang JF, Hong CZ. Myofascial low back pain. Tw J Phys Med Rehabil. 2008;36:1-14.

11. Papadopoulos EC, Khan SN. Piriformis syndrome and low back pain: a new classification and review of the literature. Orthop Clin North Am. 2004;35:65-71.

12. Tsai WC, Wang TG, Hong CZ. Myofascial trigger points in the ipsilateral gluteal muscles associated with pyogenic sacroiliitis: A case report. J Musculoske Pain. 1999;7:73-82.

13. Gunn CC. The Gunn Approach to the Treatment of Chronic Pain: Intramuscular Stimulation for Myofascial Pain of Radiculopathic Origin. London: Churchill Livingston; 1996.

14. Hong CZ. Myofascial pain therapy. J Musculoskeletal Pain. 2004;12: 37-43.

15. Hong CZ, Simons DG. Pathophysiologic and electrophysiologic mechanism of myofascial trigger points. Arch Phys Med Rehabil. 1998;79: 863-872.

16. Mense S, Simons DG. Muscle Pain: Understanding its Nature, Diagnosis, and Treatment. Philadelphia: Lippincott Williams \& Wilkins; 2001.

17. Simons DG. Clinical and etiological update of myofascial pain from trigger points. J Musculoskel Pain. 1996;4:93-121.

18. Simons DG. Diagnostic criteria of myofascial pain due to trigger points. J Musculoskel Pain. 1999;7:111-120.

19. Simons DG. New aspects of myofascial trigger points: etiological and clinical. J Musculoskel Pain. 2004;12:15-21.

20. Simons DG. New views of myofascial trigger points: etiology and diagnosis. Arch Phys Med Rehabil. 2008;89:157-159.

21. Simons DG, Travell JG, Simons LS. Travell \& Simons's Myofascial Pain and Dysfunction: The Trigger Point Manual. Baltimore: Lippincott Williams \& Wilkins; 1999.

22. Hong CZ. Research on myofascial pain syndrome. Crit Rev Phys Rehabil Med. 2008;20:343-366.

23. Cavanaugh JM, Lu Y, Chen C, Kallakuri S. Pain generation in lumbar and cervical facet joints. J Bone Joint Surg Am. 2006;88(suppl 2):63-67.

24. Mooney V, Robertson J. The facet syndrome. Clin Orthop Relat Res. 1976;115:149-156.

25. Hong CZ. Muscle pain syndromes. In: Braddom RL, editor. Physical Medicine and Rehabilitation. 4th Ed. New York: Elsevier; 2011:971-1001.

26. Boswell MV, Shah RV, Everett CR, et al. Interventional techniques in the management of chronic spinal pain: evidence-based practice guidelines. Pain Physician. 2005;8:1-47.

27. Boswell MV, Colson JD, Spillane WF. Therapeutic facet joint interventions in chronic spinal pain: a systemic review of effectiveness and complications. Pain Physician. 2005;8:101-114. 
28. Carrino JA, Morrison WB, Parker L, Schweitzer ME, Levin DC, Sunshine JH. Spinal injection procedures: volume, provider distribution, and reimbursement in the U.S. medicare population from 1993 to 1999. Radiology. 2002;225:723-729.

29. Tsai CT, Hsieh LF, Kuan TS, Kao MJ, Hong CZ. Injection into cervical facet joint region in treating shoulder pain with myofascial trigger points in the upper trapezius muscle. Orthopedics. 2009;32(8):557-565.

30. Wang NP, Kuo FC, Hsieh YL, Wu SK, Hong CZ. Treatment of piriformis myofascial pain syndrome related to lumbar facet lesion: a case report. Tw J Phys Med Rehabil. 2009;37:115-122.

31. Hong CZ. Needling Therapy for Myofascial Pain Control (Editorial). Evid Based Complement Alternat Med. 2013.

32. McCall IW, Park WM, O'Brien JP. Induced pain referral from posterior lumbar elements in normal subjects. Spine. 1979;4:441-446.

33. Mathews JA, Mills SB, Jenkins VM, et al. Back pain and sciatica: controlled trials of manipulation, traction, sclerosant and epidural injections. Br J Rheumatol. 1987;26:416-423.

34. Clarke J, van Tulder M, Blomberg S, de Vet H, van der Heijden G, Bronfort G. Traction for low back pain with or without sciatica: an updated systematic review within the framework of the Cochrane collaboration. Spine. 2006;31:1591-1599.
35. Ianuzzi A, Khalsa PS. Comparison of human lumbar facet joint capsule strains during simulated high-velocity, low-amplitude spinal manipulation versus physiological motions. Spine J. 2005;5:277-290.

36. Galiano K, Obwegeser AA, Walch C, Schatzer R, Pioner F, Gruber H. Ultrasound-guided versus computed tomography-controlled facet joint injections in the lumbar spine: a prospective randomized clinical trial. Reg Anesth Pain Med. 2007;32:317-322.

37. Jones SL. Descending noradrenergic influences on pain. Prog Brain Res. 1991;88:381-394.

38. Li A, Wang Y, Xin J, et al. Electroacupuncture suppresses hyperalgesia and spinal Fos expression by activating the descending inhibitory system. Brain Res. 2007;1186:171-179.

39. Lin JG, Chen WL. Acupuncture analgesia: a review of its mechanisms of actions. Am J Chin Med. 2008;36:635-645.

40. Lin JG, Chen WL. Review: acupuncture analgesia in clinical trials. Am J Chin Med. 2009;37:1-18.

41. Takeshige C, Sato T, Mera T, Hisamitsu T, Fang J. Descending pain inhibitory system involved in acupuncture analgesia. Brain Res Bull. 1992;29:617-634.

42. Yoshimura M, Furue H. Mechanisms for the anti-nociceptive actions of the descending noradrenergic and serotonergic systems in the spinal cord. J Pharmacol Sci. 2006;101:107-117.
Patient Preference and Adherence

\section{Publish your work in this journal}

Patient Preference and Adherence is an international, peer-reviewed, open access journal that focuses on the growing importance of patient preference and adherence throughout the therapeutic continuum. Patient satisfaction, acceptability, quality of life, compliance, persistence and their role in developing new therapeutic modalities and compounds to optimize

\section{Dovepress}

clinical outcomes for existing disease states are major areas of interest for the journal. This journal has been accepted for indexing on PubMed Central. The manuscript management system is completely online and includes a very quick and fair peer-review system, which is all easy to use. Visit http://www. dovepress.com/testimonials.php to read real quotes from published authors. 